\title{
OPEN Graphene/fluorescein dye-based sensor for detecting As(III) in drinking water
}

\author{
Madhu D. Sharma ${ }^{1}$, Sadhana S. Rayalu ${ }^{1}$, Spas D. Kolev ${ }^{2}$ \& Reddithota J. Krupadam ${ }^{1 凶}$
}

A complex of reduced graphene oxide $(\mathrm{rGO})$ and fluorescein $(\mathrm{FL})$ dye nanoparticles of size between 50 and $100 \mathrm{~nm}$ has been prepared and its sensing performance for detection of As(III) in drinking water has been reported. When As(III) binds to the rGO-FL nanoparticles the relative quenching of fluorescence was increased with increase in As(III) concentration thus provide two linear calibration ranges $\left(0-4.0 \mathrm{mmol} \mathrm{L}^{-1}\right.$ and $\left.4.0-10 \mathrm{mmol} \mathrm{L}^{-1}\right)$. The fluorescence quenching mechanism was investigated by using time-resolved fluorescence spectroscopy and molecular modeling. The detection limit of this sensor has been determined as equal to $0.96 \mu \mathrm{g} \mathrm{L}^{-1}$ which is about 10 times lower than the WHO stipulated standard for As(III) in drinking water $\left(10 \mu \mathrm{g} \mathrm{L}^{-1}\right)$. The analytical performance and potential application of the nanosensor was compared to commercial field kits used in arsenic monitoring. The sensor proposed in this study is fast, sensitive and accurate for detection of As(III) in drinking water and environmental samples.

Contamination of drinking water with toxic arsenic species has been reported across the globe ${ }^{1,2}$. The inorganic forms of arsenic exhibit higher toxicity as compared to the organic forms ${ }^{3}$. The standard prescribed for arsenic in drinking water by World Health Organization $(\mathrm{WHO})^{4}$ is $10 \mu \mathrm{g} \mathrm{L}^{-1}$. The testing of drinking water for arsenic species such low concentration is a challenge to analysts. Sophisticated instrumental techniques such as inductively coupled plasma mass spectrometry (ICP-MS) are often used to determine ultra-trace concentrations of arsenic species in water ${ }^{5}$. This method is expensive and not fit for in-situ analysis. Indeed, there is a great demand for in-situ, portable, and sensitive methods or devices for As(III) detection in drinking water and environmental samples.

Recent advancements in the fields of nanoscience, colloids and interfaces have been useful in the development of highly sensitive sensors for the detection of environmental pollutants such as endocrine disrupting chemicals (EDCs), carcinogens, pesticides, explosives, food toxins and other toxic chemicals ${ }^{6}$. The wonder material of twenty-first century is graphene which has great potential in sensor technology for detecting gases, chemicals, heavy metal ions, and other environmental pollutants. The current advances, sensitivity and selectivity of a wide variety of graphene-based sensors have been reported ${ }^{7,8}$. Ultra-sensitive detection of As(III) in the concentration range of 1.0-10 $\mathrm{nmol} \mathrm{L}^{-1}$ was reported using a graphene-lead oxide electrode ${ }^{9}$. The use of lead oxide may be instrumental in improving the sensing performance of this electrode, but it is a highly toxic compound. An aptamer based fluorimetric method has offered an impressively low detection limit of $1.3 \mathrm{pmol} \mathrm{L}^{-1}$ for As(III). In this method, the highly toxic cadmium ion was used as the aptamer conjugate to generate fluorescence signal. Another limitation of this method stems from the fact that the aptamer can be easily denatured ${ }^{10}$. A wide detection concentration range (1-500 $\mathrm{g} \mathrm{L} \mathrm{L}^{-1}$ ) of As(III) was achieved by using a Au-based nanoparticle sensor, however, the cost of measurement would be expensive because of Au was used in the sensor fabrication ${ }^{11}$. Zeng et al. reported an aptamer formulated with DNAzyme for As(III) detection in the picomolar concentration range $^{12}$. A renewable gold plated Ir-based microelectrode was developed for the detection of As(III) at concentrations between 10 and $50 \mathrm{nmol} \mathrm{L}{ }^{-1}$ at $\mathrm{pH}$ 8.0 $0^{13}$. A biosensor based on Au@Ag core-shell nanoparticles for SERS detection of As(III $)^{14}$ has exhibited a detection limit of $0.1 \mu \mathrm{g} \mathrm{L}{ }^{-1}$. A nanoprobe was fabricated with the combination of aptamers and mesoporous silica nanoparticles which showed highly sensitive detection of As(III) in aqueous solutions ${ }^{15}$.

Ezeh and Harrop was formulated a new reagent named as "ArsenoFluor1 (AF1)" to determine As(III) in organic solvents at $298 \mathrm{~K}^{16}$. This reagent emits strong fluorescence emission at $496 \mathrm{~nm}$ which is specific for As(III). The media used in this method for As(III) analysis are organic solutions which limits application of this

${ }^{1}$ Environmental Materials Division, CSIR-National Environmental Engineering Research Institute, Nehru Marg, Nagpur 440020, India. ${ }^{2}$ School of Chemistry, The University of Melbourne, Parkville, VIC 3010, Australia. ${ }^{\square}$ email: rj_krupadam@neeri.res.in 


\begin{tabular}{|l|l|l|l|}
\hline Sr. no & Sensing/detection system & Sensitivity/lower detection limit & References \\
\hline 1 & GO-PbO composite & $0.01 \mathrm{ppb}$ & 9 \\
\hline 2 & CdTe/ZnS core/shell QDs using Aptamer & $<1 \mathrm{ppb}$ & 10 \\
\hline 3 & AuNPs nanoparticle-based biosensor & $\begin{array}{l}40 \mathrm{ppb} \text { for naked eye } \\
0.6 \mathrm{ppb} \text { for colorimetric assay } \\
0.77 \mathrm{ppb} \text { for RS assay }\end{array}$ & 11 \\
\hline 4 & Aptasensor with DNAzyme canalytic amplifier & $10 \mathrm{pM}$ & 12 \\
\hline 5 & Gold plated Ir-based microelectrode (AuCs) & $<1 \mathrm{ppb}$ & 13 \\
\hline 6 & $\begin{array}{l}\text { Surface plasmon resonance (SPR) sensor using several thiol-containing } \\
\text { organic compounds }\end{array}$ & $10 \mathrm{ppb}$ & 14 \\
\hline 7 & Luminescent Bacterial Biosensor & $<1 \mathrm{ppb}$ & 15 \\
\hline 8 & ArsenoFluorl fluorescent chemical probe & $10 \mathrm{ppb}$ & 16 \\
\hline 9 & Modified Quantum dots (QDs) mixed with cyan carbon dots (CDs) & $1.7 \mathrm{ppb}$ & 17 \\
\hline 10 & rFO-FL nanosensor & $1.0 \mathrm{ppb}$ & In this study \\
\hline
\end{tabular}

Table 1. Highly sensitive arsenic detection/sensing systems reported in the literature.

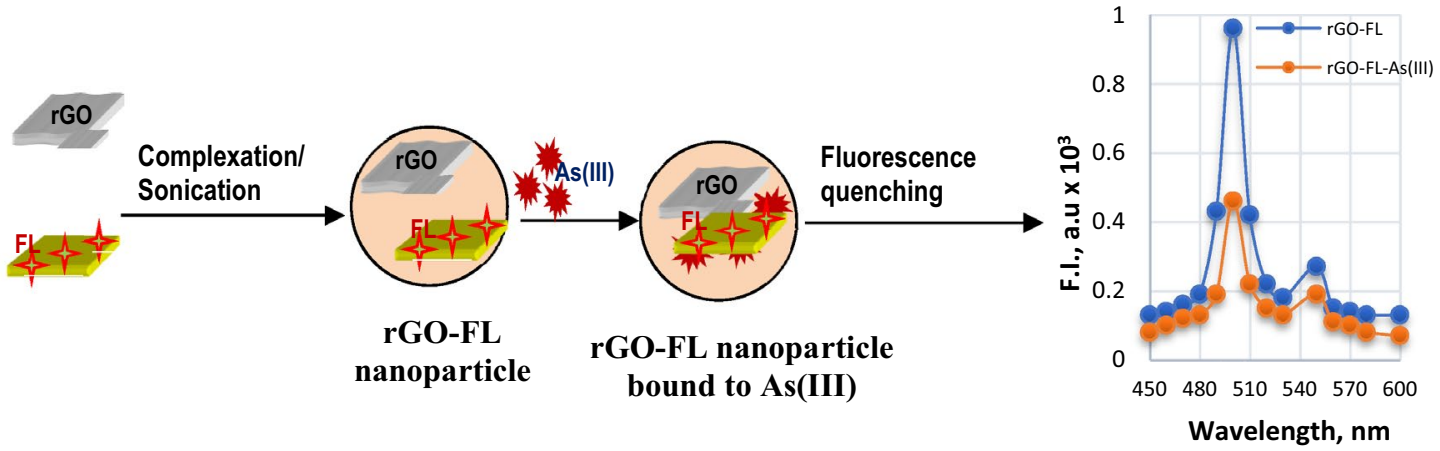

rGO, reduced graphene oxide; FL, fluorescein and As(III), arsenic (III)

Figure 1. The sensing schematic of rGO-FL nanosensor for As (III) detection.

method for water monitoring. A rapid and sensitive detection of As(III) using fluorescent test papers embedded with quantum dots was reported ${ }^{17}$. The fluorescent paper turns from red to cyan in the presence of As(III)

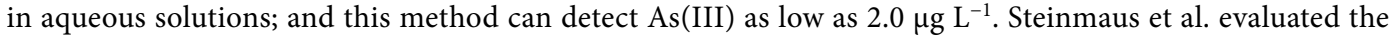
performance of two field kits for arsenic analysis (Quick Arsenic and Hach EZ) and as compared their sensing performance with atomic fluorescence spectrometric method ${ }^{18}$. Both kits have shown As(III) detection in the range of $15-20 \mu \mathrm{g} \mathrm{L}^{-1}$ which is above the WHO stipulated standard for drinking water of $10 \mu \mathrm{g} \mathrm{L}{ }^{-1}$. A list of sensor/methods for detection of As(III) in environmental samples at concentrations lower than $10 \mu \mathrm{g} \mathrm{L}^{-1}$ is given in Table 1.

In this study, we report the reduced graphene oxide ( $\mathrm{rGO}$ ) and fluorescein (FL) dye nanocomposite-based As(III) sensor. The sensing schematic of rGO-FL nanosensor for As(III) detection is given in Fig. 1. The rGO/ FL nanocomposite was characterized by using scanning electron microscope (SEM), atomic force microscope (AFM), X-ray photoluminescence spectrometer (XPS), infrared spectrometer (IR), dynamic light scattering (DLS) system and Zetanano sizer (ZNS) and fluorescence spectrophotometer (FS). The rGO/FL nanosensor respond to As(III) in aqueous solutions by quenching fluorescence emission. The mechanism of fluorescence quenching was studied using time-resolved fluorescence spectrophotometry. The stability of the rGO/ FL nanosensor in aqueous solution was investigated by using a dynamic light scattering method. The nature of interactions between the colloidal particles and As(III) was modeled using Gaussian Ver 4.21 software. The rGO/ FL nanosensor showed lower limit of detection of $0.96 \mu \mathrm{g} \mathrm{L}^{-1}$ for As(III) in drinking water, much better than that of WHO recommended standard of $10 \mu \mathrm{g} \mathrm{L} \mathrm{L}^{-1}$. The method developed for As(III) detection in this study was compared to the standard APHA Standard Method based on the use of ICP-OES/MS and portable As(III) kits/ devices used in in-situ monitoring of arsenic in drinking water and environmental samples.

\section{Methods}

Materials. Graphene was prepared from graphite flakes (purchased from Sigma-Aldrich, St. Louis, United States) by the Hummers method ${ }^{19}$. Graphene was chemically exfoliated to produce graphene oxide $(\mathrm{GO})^{20}$. The GO was reduced by using hydrazine hydrate to obtain reduced graphene oxide ( $\mathrm{rGO})^{21}$. Fluorescein dye (FL, SKU-46955) and a certified reference material (TraceCERT-71718) of As(III) were purchased from Sigma Aldrich (St. Louis, United States). The concentration of As(III) this standard solution was $1.0 \pm 0.01 \mathrm{mg} \mathrm{L}^{-1}$. Reagent grade water of quality Type I (ASTM D1193-91) was used during preparation of the rGO-FL nanoparicle solution. Reagent grade purity of water with conductivity lower than $0.01 \mu \mathrm{S} \mathrm{cm}^{-1}$ and total organic carbon lower 

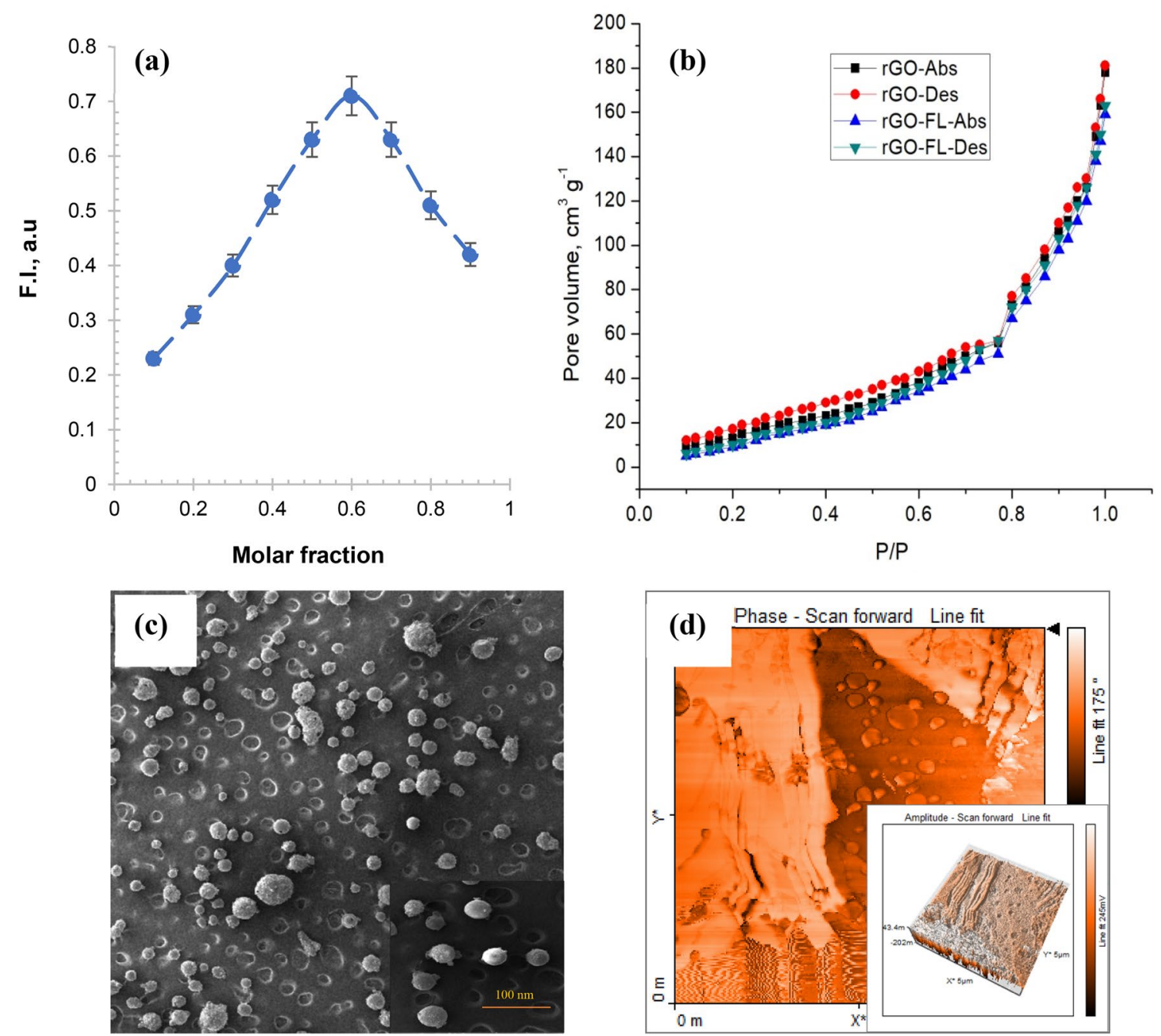

Figure 2. (a) Job's plot for optimum stoichiometric complex formation between rGO and FL. Job's plot provides qualitative and quantitative details about the stoichiometry of association between reduced graphene oxide (rGO) and ligand (Fluorescenc) to form rGO-FL complex contain $0.7 \mathrm{~mL}$ of $1 \mathrm{mmol} \mathrm{rGO}$ and $1 \mathrm{mmol}$ of fluorescein. The complex formation between rGO and FL was studied using fluorescence emission at $510 \mathrm{~nm}$ (b) Nitrogen adsorption-desorption isotherms of rGO and rGO-FL particles (c) SEM micrograph (d) AFM micrographs of rGO-FL nanoparticles.

than $20 \mu \mathrm{g} \mathrm{L}^{-1}$ was in the preparation of solutions. The $\mathrm{pH}$ of the reagent-grade water was $5.83 \pm 0.05$. The other chemicals used in this study were procured from Merck (Kenilworth, USA) and used as procured.

Preparation of graphene-dye nanosensor. Initially, the stoichiometric composition of rGO-FL nanoparticles was determined by using Job's plot $^{22}$. The optimum ratio of rGO and FL was determined by monitoring the fluorescence emission at different mole fractions. The rGO-FL nanoparticles with optimal composition were used to detect As(III) in water by measuring the change in the intensity of fluorescence quenching. It was found that the fluorescence emission at $510 \mathrm{~nm}$ showed the highest intensity for rGO-FL nanoparticles with a ratio of 6:4 (Fig. 2a). The rGO-FL nanoparticles were prepared by sonicating $6 \mathrm{~g}$ of rGO in $100 \mathrm{~mL}$ of reagent grade water for $10 \mathrm{~min}$, followed by addition of $4 \mathrm{~g}$ of fluorescein. The nanparticles were further sonicated for $10 \mathrm{~min}$. After keeping the suspension for $1 \mathrm{~h}$, the solution was filtered through Whatmann filter paper No. 41 (pore size, $20 \mu \mathrm{m}$ ). The fine particles in the filtrate were separated by centrifugation. The particles collected on the filter paper and particles collected from centrifugation were washed thoroughly with $100 \mathrm{~mL}$ of reagent-grade water. The washing was repeated 5 times and then the nanoparticles were dried in vacuum before use as the nanosensor for detection of As(III) in water.

Instruments. The surface area, pore volume and average pore diameter of rGO-FL nanoparticles were determined by using $\mathrm{N}_{2}$ adsorption isotherms obtained from an Accelerated Surface Area and Porosimetry System (Micromeritics-ASAP 2420, USA) at $77 \mathrm{~K}$. Nitrogen adsorption surface area of the nanoparticles was computed by Brunauer-Emmett-Teller (BET) equation ${ }^{23}$ and pore volumes were calculated using BarretJoyner-Haldena $(\mathrm{BJH})$ method $^{24}$. Microscopic observation of the nanoparticles was carried out using a scanning 
electron microscope (SEM) (S-2500 Hitachi, Japan). The surface morphology of the rGO-FL nanoparticles was viewed by using an atomic force microscope (AFM) (FlexAFM, Nanosurf AG, Switzerland). The micrographs of the rGO-FL nanoparticles were obtained at image pixel size $2.5 \mu \mathrm{m}$. The zeta potential of nanoparticles was measured using a two-angle particle and molecular size analyzer (Zetasizer Nano ZS, Malvern Pananalytical, United Kingdom). The infrared spectra of the rGO, rGO-FL nanoparticles and rGO-FL nanoparticles with As(III) were obtained by an infrared spectrometer (Perkin-Elmer $983 \mathrm{G}$, USA). The fluorescence emission at $510 \mathrm{~nm}$ was measured by a spectrofluorimeter (Hitachi F-7500, Tokyo, Japan) by exciting samples at $348 \mathrm{~nm}$. The dynamic light scattering (DLS) method was used to measure the particle size of the rGO-FL nanoparticles in water using a Nano size Analyzer (Horiba-SZ 100, Japan). This analyzer is equipped with a laser beam at $532 \mathrm{~nm}$. X-ray photoelectron spectroscopy (XPS) measurements of samples were performed on a spectrometer (Scienta Omicron, Germany) hyphenated with an electron spectroscopy for chemical analysis (ESCA) probe using Al- $\mathrm{K}_{\dot{\alpha}}$ radiation source to generate monochromatic beam with energy $h v=1486.6 \mathrm{eV}$.

Molecular modeling. The molecular model of the rGO-FL nanoparticles with conformational structure was developed on HyperChem Rel 8.0 software. The probable sites for As(III) binding were identified by computing the intrinsic molecular energy in a geometrically optimized rGO-FL nanoparticle ${ }^{25}$. The force fields module MM2 in the software Gaussian Ver 4.21 was used to identify the probable sites with high affinity for As(III) in water ${ }^{26}$.

Experimental procedure. A known quantity $(10 \mathrm{mg})$ of the $\mathrm{rGO}-\mathrm{FL}$ nanoparticles was added to $10 \mathrm{~mL}$ of reagent grade water and the fluorescence emission at $510 \mathrm{~nm}$ was measured using a fluorescence spectrometer. Similarly, the same amount of the rGO-FL nanoparticles was added to different volumes of reagent water and the fluorescence emissions were recorded. The agglomeration of nanoparticles in water was prevented by adding a few drops of Caster Oil (CO) during the As(III) measurement. The kinetics of aggregation was monitored by recording fluorescence quenching as a function of time.

The fluorescence emission intensity values of the rGO-FL nanoparticles $\left(\mathrm{F}_{\mathrm{o}}\right)$ and the rGO-FL-As(III) complex $\left(\mathrm{F}_{\mathrm{I}}\right)$ after the addition of different concentrations of As(III) were recorded during calibration. The $\mathrm{pH}$ effect on $\mathrm{As}$ (III) sensing was determined by varying $\mathrm{pH}$ of the $\mathrm{As}$ (III) solutions with the addition of $0.01 \mathrm{M} \mathrm{HNO}_{3}$ or $0.01 \mathrm{M} \mathrm{NaOH}$ solutions. By spiking the As(III) solution with certified reference pH buffers 4.75, 7.4 and 9.25, the fluorescence emission was recorded. The cross-selectivity experiments were performed as follows: the solution of metal ions containing all the metal ions of interest was prepared by dissolving the relevant metal salts in deionized water. The initial precipitate of metal hydroxides was dissolved by adding a few milliliters of $\mathrm{HNO}_{3}$ to achieve a final $\mathrm{pH}$ of the solution between 1.8 and 2.1. The concentration of each metal ion in the solution was equal to $1.0 \mu \mathrm{g} \mathrm{L}{ }^{-1}$. A given amount of the rGO-FL nanoparticles was added to the metal solution and the mixture was stirred by a magnetic stirrer at room temperature. Then, the residual concentration of each metal ion at predetermined time intervals was measured by ICP-OES. The quantity of each metal ion uptake per gram of rGO-FL nanoparticles was determined by the difference between the initial and final concentrations of the metal ion in the test solutions.

Interference of sample matrix parameters. The two important sample matrix parameters-otal dissolved solids (TDS) and dissolved organic matter (DOM) - which interfere during the analysis of As(III) in water samples. The interference experiments were conducted as follows: the groundwater samples collected from different locations with varied concentrations of TDS and DOC and to each sample a standard As(III) solution of concentration $1.0 \mu \mathrm{g} \mathrm{L}^{-1}$ was added. The samples with different TDS and DOC concentration were added $10 \mathrm{mg}$ of the rGO-FL nanoparticles. Humic acid (HA) was used as a representative chemical of organic matter in sample solutions. A certain quantity of HA $\left(10-500 \mu \mathrm{g} \mathrm{L}^{-1}\right)$ was added to As(III) standard solutions to examine its effect on detection of As(III) by the rGO-FL nanosensor. The groundwater samples and samples spiked with a standard As(III) solution were simultaneously analyzed and the analytical sensitivity and limits of detection of the newly developed rGO/FL sensor was determined. The rGO-FL sensor performance was compared to field kits and the Standard Method (APHA, 2017; Method, 3120).

\section{Results and discussion}

Properties of the rGO/FL nanosensor. The nanoparticles were spherical in shape with the size varied between 50 and $100 \mathrm{~nm}$. The particles of size $<50 \mathrm{~nm}$ was about $65 \%$ and the average particle diameter of rGO/ FL nanoparticles was $28.9 \mathrm{~nm}$. The specific surface area of rGO-FL nanoparticles was $164 \mathrm{~m}^{2} \mathrm{~g}^{-1}$. The surface area of rGO without FL was $182 \mathrm{~m}^{2} \mathrm{~g}^{-1}$ and higher surface area was attributed to the higher hydrophilicity of the rGO-FL nanoparticles which facilitated their aggregation in water. The $\mathrm{N}_{2}$ adsorption-desorption curves followed type IV model ${ }^{27}$ with a weak hysteresis loop in the relative pressure range $0.5-1.0$ (Fig. 2b). The SEM micrographs of rGO-FL nanoparticles showed the existence of micro/meso-pores (Fig. 2c). The topology of $\mathrm{rGO} / \mathrm{FL}$ nanoparticles were analyzed with high resolution AFM. The micrographs of AFM showed the scattered cavities with a depth of $5 \pm 2 \mathrm{~nm}$. It can be hypothesized that these cavities could be preferentially binding with As(III) species (Fig. 2d). The AFM micrographs of 3D views further confirm the existence of cavities on the surface of rGO-FL nanoparticles. The zeta potential of the rGO nanoparticles decreased with an increase in $\mathrm{pH}$ and reached isoelectric point at pH 4.48 (Fig. 3a). When the rGO nanoparticles were complexed with FL, the isoelectric point was shifted upward from 4.48 to 5.27. The rGO-FL nanoparticles were reported to exhibit high stability between $\mathrm{pH} 6$ to $\mathrm{pH} 8$ where the zeta potential was below $-30 \mathrm{mV}$. The rGO/FL nanoparticles improved the dispersibility and stability of the particles due to their mutual repulsion in water ${ }^{28}$. The infrared spectra of rGO-FL nanoparticles show the stretching vibration peaks at $3460(-\mathrm{C}=\mathrm{O}-), 3429 \mathrm{~cm}^{-1}(-\mathrm{O}-\mathrm{H}), 1721 \mathrm{~cm}^{-1}$ 

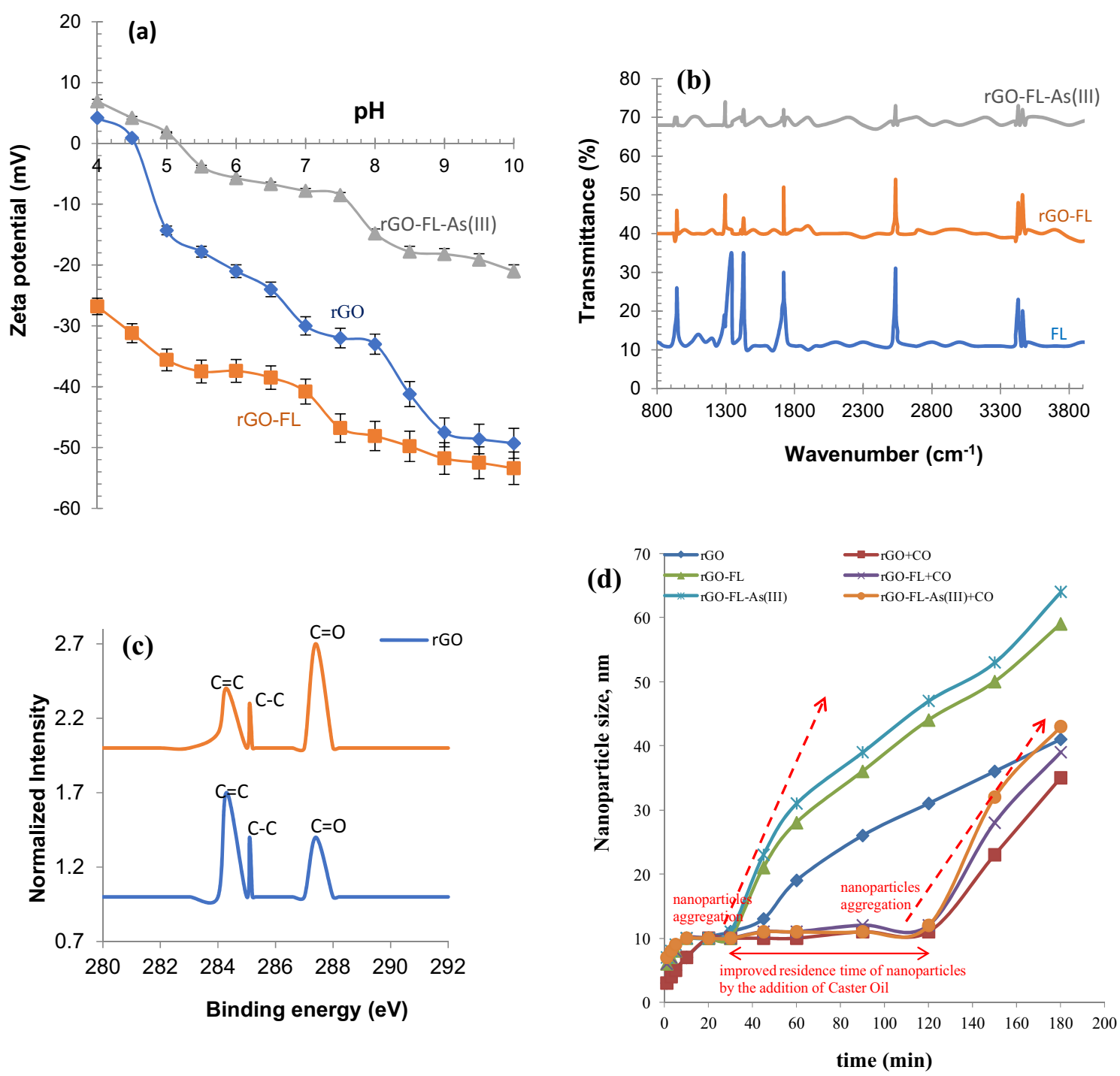

Figure 3. (a) Zeta-potential of rGO, rGO-FL and rGO-FL-As(III) nanoparticles (b) Infrared spectra of FL, rGO-FL and rGO-FL complex with As(III) (c) XPS spectra of rGO and rGO-FL (d) Dynamic light scattering results illustrating the growth of the rGO-FL nanoparticles as a function of time.

$(\mathrm{C}=\mathrm{O}-\mathrm{H}), 1429(\mathrm{C}-\mathrm{O})$, and $1296 \mathrm{~cm}^{-1}(-\mathrm{C}-\mathrm{H})$ indicating the presence of fluorescein functionalities on the surface of the rGO particles. These peaks were reduced in intensity or disappeared after exposure of the particles to $\mathrm{As}(\mathrm{III})$ (Fig. 3b). The XPS measurements showed a weak peak of $\mathrm{O}^{1} \mathrm{~s}$ for the $\mathrm{rGO}-\mathrm{FL}$ nanoparticles thus indicating low residual oxygen functionalities (Fig. 3c). The $\mathrm{C}^{1} s$ XPS spectra of the rGO and rGO-FL nanoparticles showed the peaks specific to carbon functionalities at $284.3 \mathrm{eV}$ ( $\mathrm{C}$ in $\mathrm{C}=\mathrm{C}$ bond), $285.1 \mathrm{eV}$ ( $\mathrm{C}$ in $\mathrm{C}-\mathrm{C}$ bond) and $287.4 \mathrm{eV}(\mathrm{C} \text { in } \mathrm{C}=\mathrm{O} \text { bond })^{29}$. The intensity of the peak at $283.3 \mathrm{eV}$ was reduced significantly in $\mathrm{rGO}-\mathrm{FL}$ nanoparticles due to shifting of $s p^{2}$ hybridization of $\mathrm{C}=\mathrm{C}$ to $s p^{3}$ hybridization of $\mathrm{C}-\mathrm{C}$. This XPS data provide a proof of the existence of more $\mathrm{C}=\mathrm{O}$ functionalities in the $\mathrm{rGO}-\mathrm{FL}$ nanoparticles attribute to the formation of a rGO/FL complex. The DLS results have shown that the nanoparticles interact with each other and after 45 min the particles start to agglomerate in water. To prevent this agglomeration, $10 \mathrm{~mL}$ of Caster Oil (CO) was used in $1.0 \mathrm{~L}$ of $\mathrm{rGO}-\mathrm{FL}$ nanoparticle solution. The addition of CO prolonged the particle agglomeration time from 45 to $120 \mathrm{~min}$ (Fig. 3d). The maximum particle size, measured by using DLS, ranged from 25 to $57 \mathrm{~nm}$. The DLS particle size distribution data indicate that $20 \%$ increase in the size of the rGO-FL complexed with As(III) compared to solitary rGO-FL nanoparticles. An increase in the size of nanoparticles facilitates the agglomeration ${ }^{30}$.

Interaction of the rGO-FL complex with As(III). When the rGO-FL nanoparticles interact with As(III) the fluorescence emission was quenched. This quenching phenomenon was characterized by (1) a red shift of the fluorescence emission of rGO from 453 to $510 \mathrm{~nm}$ when rGO was complexed with FL (Fig. 4a) and (2) the quenching of the fluorescence of the rGO-FL particles upon binding with As(III). The fluorescent titration of rGO-FL nanoparticles with As(III) have shown that the intensity of fluorescence emission at $510 \mathrm{~nm}$ decreased when the concentration of As(III) increased from $0.1 \mu \mathrm{g} \mathrm{L}^{-1}$ to $100 \mathrm{mg} \mathrm{L}^{-1}$ (Fig. 4b). The fluorescence quenching would be attributed to the binding of As(III) on to the surface functional groups of the rGO-FL nanoparticles. 

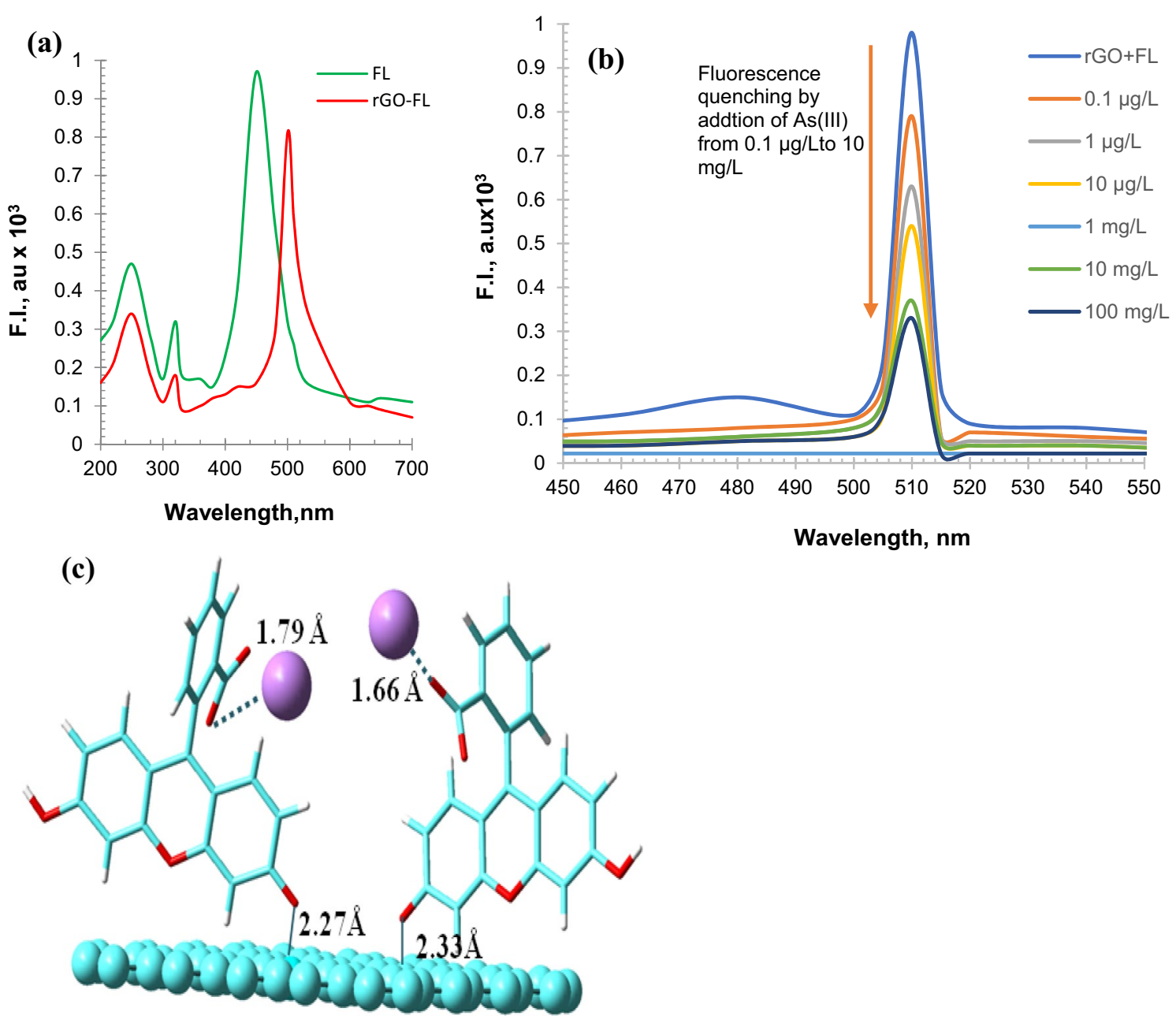

Figure 4. (a) Fluorescence emission spectra of FL and rGO-FL showing red shift during formation of nanocomposite (b) Fluorescence titration spectra of rGO and FL in aqueous solution. The fluorescence emission was observed at $510 \mathrm{~nm}$ when the sample was excited at $348 \mathrm{~nm}$ and the increase in concentration of As(III) reduce the fluorescence intensity (c) Molecular model of rGO-FL nanoparticles interaction with As(III) simulated in vacuum using Gaussian Ver. 4.2.1 software; https://gaussian.com/utils.

The binding of carboxylic acid and ketonic groups of FL to the rGO nanoparticles red shifted in the fluorescence emission. The electronegativity of the rGO-FL nanoparticles was also increased. Furthermore, molecular modeling showed the rGO-FL nanoparticles interact with arsenic in the neutral arsenious acid $\left(\mathrm{H}_{3} \mathrm{AsO}_{3}\right)$ form which is dominant at $\mathrm{pH}$ between 5 and 7 in natural waters. This interaction facilitate transfer of energy between rGO-FL nanoparticles and As(III) thus reducing the distance between them from 2.33 to $2.27 \AA$ (Fig. $4 \mathrm{c}$ ). The rGO-FL nanoparticles form a flexible bi-layer structure in which the $-\mathrm{COOH},-\mathrm{OH}$ and $=\mathrm{O}$ functionalities of $\mathrm{FL}$ are bound to the $-\mathrm{CONH}_{2}$ and $=\mathrm{C}=\mathrm{O}-$ groups of $\mathrm{rGO}$. These model findings were consistent with the infrared spectra of the rGO-FL particles prior and after complexation with As(III) (Fig. 3b). The graphene performs two important functions. They are (1) providing high surface area $\left(164 \mathrm{~m}^{2} \mathrm{~g}^{-1}\right)$ substrate for hosting fluorescein dye and this dye interacts with As(III) species in the aqueous solution and (2) the graphene interaction with FL dye red shift the fluorescence signal which is represents stabilized and quantifiable fluorescence quenching as shown in Fig. 4a.

Based on the Job's plot, the rGO and FL ratio in the nanoparticles was found to be $6: 4$ and the formation of rGO-FL complex was evidenced by the following experimental results: (1) the isoelectric point of rGO was shifted from $\mathrm{pH} 4.48$ to $\mathrm{pH} 5.27$ after the formation of rGO-FL complex (2) presence of infrared peaks at 3460 $(-\mathrm{C}=\mathrm{O}-), 3429 \mathrm{~cm}^{-1}(-\mathrm{O}-\mathrm{H}), 1721 \mathrm{~cm}^{-1}(\mathrm{C}=\mathrm{O}-\mathrm{H}), 1429(\mathrm{C}-\mathrm{O})$, and $1296 \mathrm{~cm}^{-1}(-\mathrm{C}-\mathrm{H})$ reflecting the fluorescein functionalities in the rGO-FL complex and (3) the XPS peak at $283.3 \mathrm{eV}$ was reduced significantly in rGO-FL particles due to change of $s p^{2}$ to $s p^{3}$ hybridization of $\mathrm{C}-\mathrm{C}$ indicating more $\mathrm{C}=\mathrm{O}$ functionalities ${ }^{31}$. Furthermore, bonding between rGO and FL was established by the molecular model which is complemented with fluorescence red shift, i.e., shift from 453 to $510 \mathrm{~nm}$ when the rGO forms a complex with FL.

Effect of $\mathrm{pH}$. The fluorescence quenching of a solution containing $0.1 \mu \mathrm{g} \mathrm{L} \mathrm{L}^{-1} \mathrm{As}$ (III) and $100 \mathrm{mg} \mathrm{L}^{-1} \mathrm{rGO}-\mathrm{FL}$ nanoparticles increased with $\mathrm{pH}$ between 3.0 to 8.0 when As(III) was present in the form of the neutral arseni- 

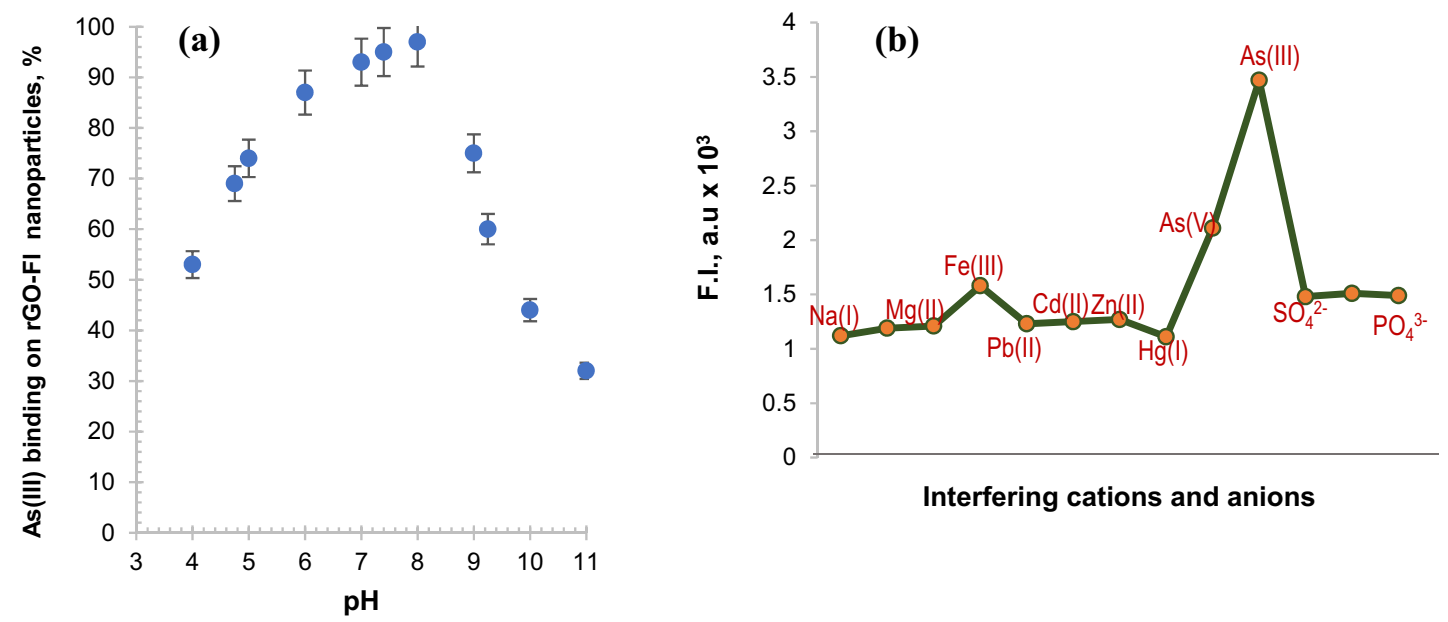

Interfering cations and anions
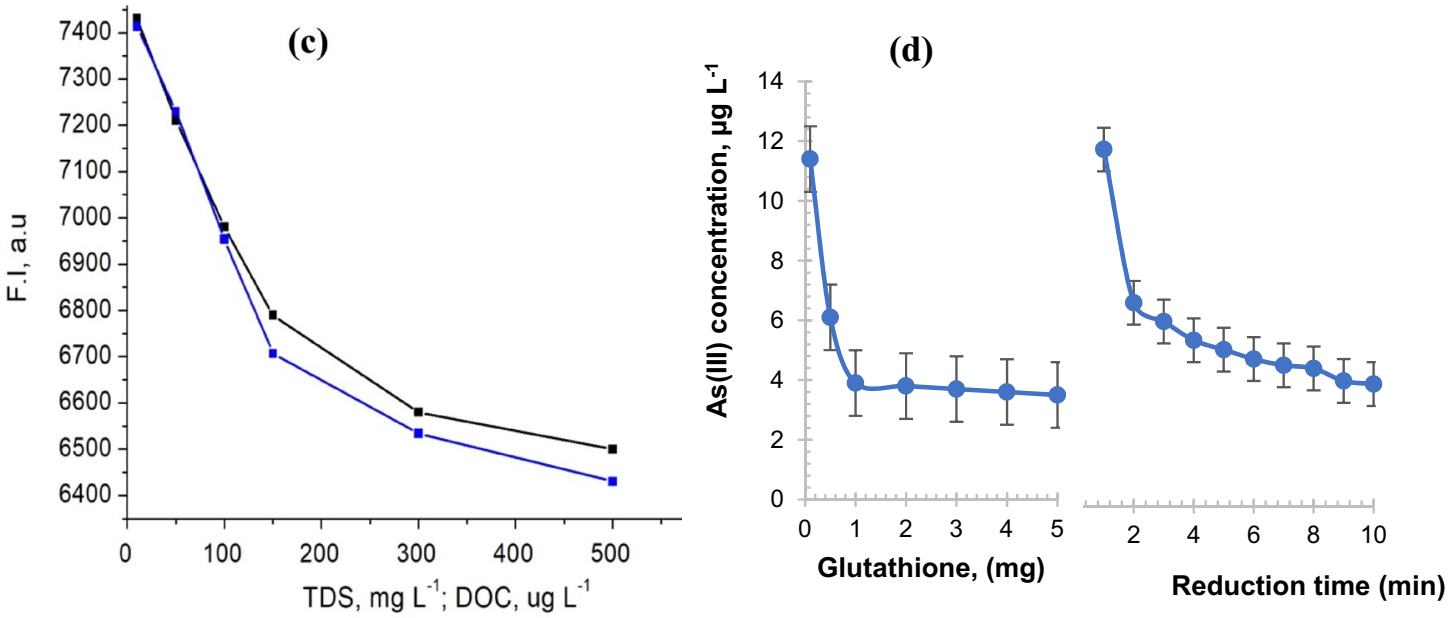

Figure 5. (a) Effect of $\mathrm{pH}$ on the fluorescence emission of rGO-FL nanoparticles (b) Interference of metal ions and common anion during detection of As(III) by the rGO-FL nanoparticle sensor (c) Interference of total dissolved solids (TDS) and dissolved organic carbon (DOC) during As(III) detection by using rGO-FL nanoparticle sensor (d) quantity of glutathione required for reduction of $\mathrm{As}(\mathrm{V})$ to $\mathrm{As}(\mathrm{III})$ and the time of reduction.

ous acid $\left(\mathrm{H}_{3} \mathrm{AsO}_{3}\right)$ and then declined further with increase in $\mathrm{pH}$ from 8.0 to 10.0 (Fig. 5a). The decline could be explained by the deprotonation of $\mathrm{H}_{3} \mathrm{AsO}_{3}$ resulting in the negatively charged $\mathrm{H}_{2} \mathrm{AsO}_{3}{ }^{-}$anion being repelled by the negatively charged nanoparticles. At $\mathrm{pH}<8.0$, the size of the nanoparticles was small $(20 \mathrm{~nm})$ and increased to $80 \mathrm{~nm}$ at $\mathrm{pH} 10.0$. When the nanoparticle increases in size it would be repelling anions e.g., sulphate, nitrate and phosphate ${ }^{32}$. The change in $\mathrm{pH}$ has no significant effect on the quantum confinement of the rGO-FL particles particularly in the $\mathrm{pH}$ range $6.5-8.5$ which is the range practically required for drinking water quality testing.

Selectivity of the nanosensor. The effect of other metal ions during detection of As(III) in water was investigated by using a competitive binding assay. The rGO-FL nanoparticles selectively bind the target As(III) at the concentration of $1.0 \mu \mathrm{g} \mathrm{L} \mathrm{L}^{-1}$ in the presence of other metal ions (of concentration $1.0 \mu \mathrm{g} \mathrm{L}^{-1}$ of each metal ion) and $\mathrm{As}(\mathrm{V})$. The experimental data, presented in Fig. 5b, indicate that none of the metal ions have a significant effect on the selective sensing of As(III) in water. The slight reduction in sensing of As(III) was found in the co-existence of anions and cations may be attributed to competition for adsorption sites between the co-existing ions and arsenic species. The As(III) species have less electronegativity (1.549) compared with As(V) species (2.40) and other metals. The zeta potential measurement for net negative charge of the rGO-FL nanoparticles further confirmed their preferable binding to As(III) species in water (Fig. 3a). This statement was furthermore confirmed by the interference of commonly found anions in water i.e., sulphate, nitrate and phosphate. The interference of these anions was higher than the other metal ions. There is another approach based on quantum confinement which is size dependent phenomena ${ }^{33}$. The rGO nanoparticles containing FL cause intrinsic fluorescence emission due to conjugated $\pi$-domains. The anionic species (sulphate, nitrate and phosphate) are potential interferants and therefore it was found that these anions have shown higher interference compared to the metal cations. 


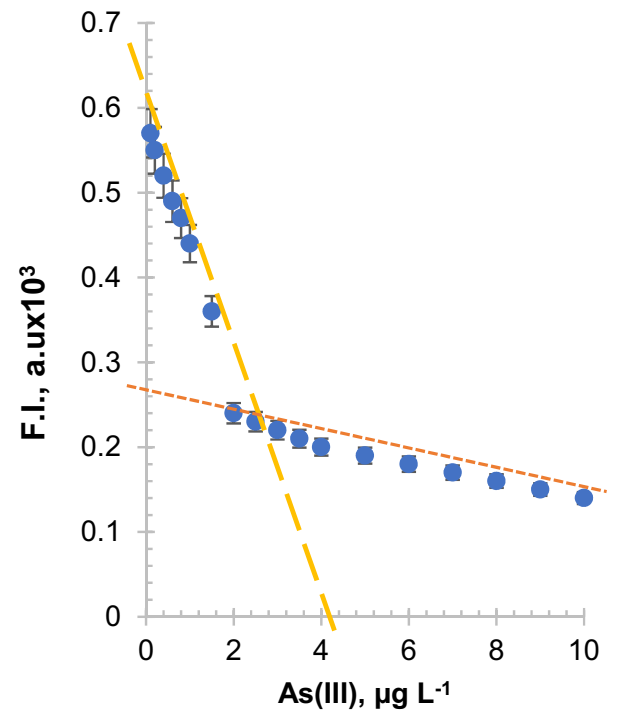

Figure 6. The Stern-Volmer plot of the quenching of the fluorescence emission of rGO-FL nanoparticles during adsorption of As(III) in aqueous solutions.

Effect of sample matrix parameters. To test the practical application of the rGO-FL nanoparticles as sensitive sensors, we used groundwater samples collected from different parts of India and then samples were spiked with standard As(III) of concentration $0.1 \mu \mathrm{g} \mathrm{L}{ }^{-1}$. The sample matrix parameters, total dissolved solids (TDS) and dissolved organic carbon (DOC), were determined by using the Standard Methods ${ }^{5}$. It was found that the groundwater samples with TDS value above $1500 \mathrm{mg} \mathrm{L}^{-1}$ interfere in As(III) detection significantly. The interference of DOC was more pronounced than the TDS. At $250 \mu \mathrm{g} \mathrm{L}^{-1}$ of DOC in the water sample, the fluorescence emission was reduced to $40 \%$. Figure $5 \mathrm{c}$ show the effect of DOC on sensing performance of rGO-FL nanoparticles. The nanoparticle sensor lost its sensing below $50 \%$ when the DOC concentration was reached to $200 \mu \mathrm{g} \mathrm{L}^{-1}$. This may be due to fast and strong bond formation between the organic moieties of HA with As(III) as compared to TDS with the rGO-FL nanoparticles. The interference of TDS and DOC during detection of As(III) in water by the proposed sensing material is quite significant. The boundary concentration of TDS and DOC were $1500 \mathrm{mg} \mathrm{L}^{-1}$ and $250 \mu \mathrm{L}^{-1}$ for water sample. The sample pre-treatment would be proposed to improve the detection of $\mathrm{As}(\mathrm{II})$ in water, when the samples were collected from natural resources with high TDS and DOC concentration.

Sample preparation for As(III). Since As(V) species are dominant in natural waters and it is necessary to reduce $\mathrm{As}(\mathrm{V})$ to $\mathrm{As}(\mathrm{III})$ for improving the detection of the rGO-FL nanoparticles. As (III) is highly toxic as compared to As (V). Even though, natural water contains As (V) as the dominant species, the existence of As (III) is reported as a minor fraction. Indeed, the groundwater resources where anoxic conditions prevail, the As(III) is the dominant arsenic species. Many Asian regions depend on groundwater resources for drinking purpose. With this context, the proposed sensor has importance to detect traces of As(III) species in the public health point of view. Glutathione was used in this study to reduce $\mathrm{As}(\mathrm{V})$ to $\mathrm{As}(\mathrm{III})$. The concentrations of the reductant and time for reduction were optimized. The quantity of glutathione required for $100 \mathrm{~mL}$ of water sample was $6.3 \mathrm{mg}$ and the time required for reduction was 2 min when the concentration of $\mathrm{As}(\mathrm{V})$ was $10 \mathrm{mg} \mathrm{L}^{-1}$ (Fig. 5d). In this study high concentration of As(III) solution was chosen since it was approximately 10 times higher than the concentration of As(III) in groundwater samples which were the realistic concentration in Bengal region in India. The quality control/assurance of experiments were conducted as per the Standard Methods (APHA, 2017; 23rd ds. $)^{5}$.

Analytical figures of merits. The Stern-Volmer plot of rGO-FL fluorescence emission versus the concentration of As(III) have shown the typical trend of fluorescence quenching (Fig. 6). A linear plot with a slope of $0.98 \times 10^{-7} \mathrm{M}$ was obtained. This slope indicates the formation of a stable complex between the rGO-FL and As(III). The limit of detection was calculated from the ordinate intercept of linear regression between the fluorescence intensity of rGO-FL nanoparticles versus concentration of As(III). A signal-to-noise ratio is calculated based on fluorescence peak height quenched during the addition of standard As(III) solution and measured from extrapolated baseline signal equal to half-height of the peak-to-leak background noise. The detection limit was computed from the relationship pf $3 \mathrm{~S}_{\mathrm{B}} / \mathrm{S}$. The limit of minimum quantification of As(III) could be detected by the rGO-FL nanoparticles was $0.098 \mu \mathrm{g} \mathrm{L}^{-1}$; and this lower detection limit is about 10 times better than the WHO guidelines i.e., $10 \mu \mathrm{g} \mathrm{L}-1$.

The analytical performance of the rGO-FL nanosensor was compared with the Standard Method (APHA, 2017: Method 3120) and two different types of field kits (Quick Arsenic and Hach EZ) and in-situ devices (Wagtech Digital and Chem-In Corp) ${ }^{34,35}$. The detection limit for As(III) of the methods mentioned above varied between $0.1 \mu \mathrm{g} \mathrm{L}^{-1}$ and $10 \mathrm{mg} \mathrm{L}^{-1}$. The rGO-FL nanoparticles can be added to the sample without any sample 


\begin{tabular}{|c|c|c|c|c|c|c|}
\hline Method/sensor/kit & Limits of detection, $\mathrm{mg} \mathrm{L}^{-1}$ & $\mathbf{M U}^{*}$ & LOD, $\mu \mathrm{g} \mathrm{L}^{-1}$ & Approx. Cost, USD & Remarks & References \\
\hline ICP-OES & $0.5-100$ & \pm 0.2 & 50 & $6-8$ & $\begin{array}{l}\text { Interference of other metals } \\
\text { Expensive } \\
\text { Skilled manpower and advanced equipment }\end{array}$ & 6 \\
\hline ICP-MS & $0.001-100$ & \pm 0.01 & 1 & $8-10$ & $\begin{array}{l}\text { Expensive } \\
\text { Advanced equipment } \\
\text { Skilled manpower }\end{array}$ & 6 \\
\hline Hach EZ kit & $15-50$ & \pm 1.5 & 150 & $4-5$ & Do not meet WHO Standard for drinking water, $10 \mu \mathrm{g} \mathrm{L}^{-1}$ & 18 \\
\hline Quick Arsenic & $12-50$ & \pm 0.9 & 200 & $4-5$ & Do not meet WHO Standard for drinking water, $10 \mu \mathrm{g} \mathrm{L}^{-1}$ & 18 \\
\hline Wagtech Digital & $18-40$ & \pm 1.1 & 200 & $3-4$ & Do not meet WHO Standard for drinking water, $10 \mu \mathrm{g} \mathrm{L}^{-1}$ & 26 \\
\hline Chem-In Corp & $20-50$ & \pm 1.4 & 150 & $3-4$ & Do not meet WHO Standard for drinking water, $10 \mu \mathrm{g} \mathrm{L}^{-1}$ & 34 \\
\hline rGO-FL nanosensor & $0.001-10$ & \pm 0.04 & 1.0 & $1-2$ & $\begin{array}{l}\text { Highly sensitive and meet the WHO drinking water quality } \\
\text { standard } \\
\text { Other metals interference is negligible } \\
\text { Reusable sensing materials }\end{array}$ & In this study \\
\hline
\end{tabular}

Table 2. Comparison of performance and cost of As(III) determination using various recently reported methods/sensors and field kits. ${ }^{*} \mathrm{MU}$, measurement of uncertainty was calculated according to the procedure given in Ref. ${ }^{13}$. The number of samples which were tested was 5 . Out of 5 samples, 2 samples were reagent water spiked with As(III) standard of different concentrations and remaining 3 samples collected from different locations in India. Each sample was tested repeatedly for seven times $(n=7)$.

\begin{tabular}{|c|c|c|c|c|}
\hline Sample & As(III) added, $\mu \mathrm{g} \mathrm{L}^{-1}$ & As(III) determined, $\mu \mathrm{g} \mathrm{L}^{-1}$ & Recovery, \% & Remarks \\
\hline \multirow{3}{*}{ G-1 } & 0 & $4.08 \pm 0.12$ & N/A0 & \multirow{3}{*}{$\begin{array}{l}\text { TDS, } 210 \mathrm{mg} \mathrm{L}^{-1} \\
\text { DOC, } 60 \mu \mathrm{g} \mathrm{L}^{-1} ; \mathrm{pH}, 6.9\end{array}$} \\
\hline & 0.1 & $4.14 \pm 0.27$ & 99.7 & \\
\hline & 10 & $14.15 \pm 0.25$ & 100.3 & \\
\hline \multirow{3}{*}{ G-2 } & 0 & $5.98 \pm 0.15$ & N/A & \multirow{3}{*}{$\begin{array}{l}\text { TDS, } 550 \mathrm{mg} \mathrm{L}^{-1} ; \\
\text { DOC, } 90 \mu \mathrm{g} \mathrm{L}^{-1} ; \mathrm{pH}, 7.5\end{array}$} \\
\hline & 0.1 & $6.12 \pm 0.24$ & 101.8 & \\
\hline & 10 & $15.99 \pm 0.33$ & 99.8 & \\
\hline \multirow{3}{*}{ G-3 } & 0 & $3.11 \pm 0.1$ & N/A & \multirow{3}{*}{$\begin{array}{l}\text { TDS, } 2100 \mathrm{mg} \mathrm{L}^{-1} ; \\
\text { DOC, } 250 \mu \mathrm{g} \mathrm{L}^{-1}, \mathrm{pH}, 7.2\end{array}$} \\
\hline & \begin{tabular}{|l|l|}
0.1 \\
\end{tabular} & $3.15 \pm 0.21$ & 100.4 & \\
\hline & 10 & $13.21 \pm 0.27$ & 101.1 & \\
\hline \multirow{2}{*}{ As(III) Std. TraceCERT(R)_ 72718} & 0.1 & $0.97 \pm 0.13$ & 99.7 & \multirow{2}{*}{$\begin{array}{l}\text { TDS, } 20 \mathrm{mg} \mathrm{L}^{-1} ; \\
\text { DOC, }<10 \mu \mathrm{g} \mathrm{L}^{-1} ; \mathrm{pH}, 5.9\end{array}$} \\
\hline & 10 & $9.98 \pm 0.11$ & 99.3 & \\
\hline
\end{tabular}

Table 3. Determination of As(III) in original and spiked groundwater samples and a standard reference material (TraceCERT ${ }^{\oplus}-71718$ with the concentration of $10 \mathrm{mg} \mathrm{L}^{-1}$ 0using rGO-FL nanoparticle based fluorescence sensor. G-1 Groundwater sample was collected from the rural area near Nagpur, Maharashtra, India, G-2 the groundwater sample was collected from urban area near Nagpur, Maharashtra, India, G-3 the sample was collected near coastal area at Bhadbhut, Gujarat, India, TDS total dissolved solids, DOC dissolved organic carbon.

pretreatment followed by directly monitoring the fluorescence signal. The detection limits of the method is quite suitable for real samples analysis and the value is about 10 times higher sensitivity as compared to the WHO standard for drinking water i.e., $10 \mu \mathrm{g} \mathrm{L}^{-1}$. Unlike the APHA standard method, the proposed method does not require advanced instrumentation (ICP-MS), high energy demand and skilled manpower. The measurement of uncertainty of the proposed method is quite low compared with the standard method and the kits/devices ${ }^{36}$. Even though, the field kits and devices are very comfortable for in-situ monitoring, due to their lower sensitivity for As(III) and high cost prevents wide field applications. The summary of analytical figures of merits of the newly developed sensor and other methods were given in Table 2. Overall, the new sensor proposed in this study is inexpensive, simple to prepare and use, environment-friendly and sensitive enough to meet the regulatory standard for As(III) analysis in environmental and drinking water.

Analysis of environmental samples. To demonstrate the feasibility of the rGO-FL nanosensor, three real groundwater samples were collected from different parts of India and were analyzed. Table 3 lists the concentration of As(III) found in real samples which varied between 1.0 and $20 \mu \mathrm{g} \mathrm{L}{ }^{-1}$. The accuracy of the sensor performance was evaluated by a recovery test using spiked groundwater samples with two different concentrations, i.e., 1.0 and $10 \mu \mathrm{g} \mathrm{L}{ }^{-1}$. The recoveries ranged between 99 and $101 \%$ thus indicating satisfactory accuracy. 


\section{Conclusions}

The graphene-dye nanosensor is useful to detect ultra-trace concentrations of As(III) in drinking water and environmental samples and the proposed detection is sensitive compared to the Standard Methods (APHA, 2017) and commercially used field kits/devices. The two important features of this sensor responsible for such high sensitivity. They are (1) the rGO-FL particles produce very strong and distinct fluorescence emission at $510 \mathrm{~nm}$ and (2) interaction of As(III) with the rGO-FL nanoparticles is specific and linearly quenches fluorescence emission with an increase in the As(III) concentration in the water samples/standards in water samples. The time-resolved fluorescence investigation suggested that the nanoparticle agglomeration could be prevented up to $120 \mathrm{~min}$ by adding traces of castor oil. In case of high $\mathrm{As}(\mathrm{V})$ concentration in the water samples, a simple natural glutathione reductant would be sufficient to convert $\mathrm{As}(\mathrm{V})$ to $\mathrm{As}(\mathrm{II})$ within $10 \mathrm{~min}$. The proposed new sensor is highly sensitive and cost-effective for monitoring of As(III) in drinking water and environmental samples.

Received: 28 May 2021; Accepted: 2 August 2021

Published online: 27 August 2021

\section{References}

1. Shahid, M. et al. A meta-analysis of the distribution, sources and health risks of arsenic-contaminated groundwater in Pakistan. Environ. Pollut. 242, 307-319. https://doi.org/10.1016/j.envpol.2018.06.083 (2018).

2. Hughes, M. F. Arsenic toxicity and potential mechanisms of action. Toxicol. Lett. 133, 1-16. https://doi.org/10.1016/S0378-4274(02) 00084-X (2000).

3. Oremland, R. S. \& Stolz, J. F. The ecology of arsenic. Science 300, 939-944. https://doi.org/10.1126/science.1081903 (2003).

4. World Health Organization (2003). Arsenic in drinking water: background document for development of WHO guidelines for drinking water quality. Doc No.: WHO/SDE/WSH/ 03.04/75. http://www.who.int/iris/handle/10665/75375.

5. American Public Health Association (APHA). Water and Wastewater Quality Analysis. 2017, 23rd eds. Method: 3120.

6. Maduraiveeran, G. \& Jin, W. Nanomaterials based electrochemical sensor and biosensor platforms for environmental applications. Trends Environ. Anal. Chem. 13, 10-23. https://doi.org/10.1016/j.teac.2017.02.001 (2017).

7. Krishnan, S. K., Singh, E., Singh, P., Meyyappan, M. \& Nalwa, H. S. A review on graphene-based nanocomposites for electrochemical and fluorescent biosensors. RSC Adv. 9, 8778-881. https://doi.org/10.1039/C8RA09577A (2019).

8. Singh, E. \& Nalwa, H. S. (eds) Nanomaterials-Based Flexible and Multifunctionall Sensors (American Scientific Publisher, 2019).

9. Ramesha, G. K. \& Sampath, S. In-situ formation of graphene-lead oxide composite and its use in trace arsenic detection. Sens. Actuators B Chem. 160, 306-311. https://doi.org/10.1016/j.snb.2011.07.053 (2011).

10. Pooja, D. et al. A "Turn-On" thiol functionalized fluorescent carbon quantum dot based chemosensory system for arsenic detection. J. Hazard. Mater. 328, 117-126. https://doi.org/10.1016/j.hazmat.2017.01.015 (2018).

11. Wu, Y., Liu, L., Zhao, S., Wang, F. \& Zhou, P. Ultrasensitive aptamer biosensor for arsenic(III) detection in aqueous solution based on surfactant-induced aggregation of gold nanoparticles. Analyst 137, 4171-4178. https://doi.org/10.1039/C2AN35711A (2012).

12. Zeng, L., Zhou, D., Gong, J., Liu, C. \& Chen, J. Highly sensitive aptasensor for trace arsenic(III) detection using DNAzyme as the biocatalytic amplifier. Anal. Chem. 91(3), 1724-1727. https://doi.org/10.1021/acs.analchem.8b05466 (2019).

13. Touilloux, R., Tercier-Waeber, M. L. \& Bakker, E. Direct arsenic(III) sensing by a renewable gold plated Ir-based microelectrode. Analyst 140, 3526-2534. https://doi.org/10.1039/C5AN00151J (2015).

14. Song, L., Mao, K., Zhou, X. \& Hu, J. A novel biosensor based on Au@Ag core-shell nanoparticles for SERS detection of arsenic (III). Talanta 146, 285-290. https://doi.org/10.1016/j.talanta.2015.08.052 (2016).

15. Oroval, M. et al. Selective fluorogenic sensing of As(III) using aptamer-capped nanomaterials. ACS Appl. Mater. Interfaces 9(13), 11332-11336. https://doi.org/10.1021/acsami.6b15164 (2017).

16. Ezeh, V. C. \& Harrop, C. C. A sensitive and selective fluorescence sensor for the detection of Arsenic(III) in organic media. Inorg. Chem. 51(3), 1213-1215. https://doi.org/10.1021/ic2023715 (2012).

17. Zhou, Y. et al. Color-multiplexing-based fluorescent test paper: Dosage-sensitive visualization of Arsenic(III) with discernable scale as low as 5 ppb. Anal. Chem. 88(12), 6105-6109. https://doi.org/10.1021/acs.analchem.6b01248 (2016).

18. Steinmaus, C. M., George, C. M., Kalman, D. A. \& Smith, A. H. Evaluation of two new arsenic field test kits capable of detecting arsenic water concentrations close to $10 \mu \mathrm{g} / \mathrm{L}$. Environ. Sci. Technol. 40(10), 3362-3366. https://doi.org/10.1021/es060015i (2006).

19. Guerrero-Contreras, J. \& Caballero-Briones, F. Graphene oxide powders with different oxidation degree, prepared by synthesis variations of the Hummers method. Mater. Chem. Phys. 153, 209-220. https://doi.org/10.1016/j.matchemphys.2015.01.005 (2015).

20. Marcano, D. C. et al. Improved synthesis of graphene oxide. ACS Nano 4(8), 4806-4814. https://doi.org/10.1021/nn 100666368 (2010).

21. Park, S. et al. Hydrazine-reduction of graphite and graphene oxide. Carbon 49(9), 3019-3023. https://doi.org/10.1016/j.carbon. 2011.02.071 (2011).

22. Maccarthy, P. Simplified experimental route for obtaining Job’s curves. Anal. Chem. 50(14), 2165. https://doi.org/10.1021/ac500 $36 \mathrm{a} 059$ (1978).

23. Bhambhani, M. R., Cutting, P. A., Sing, K. S. W. \& Turk, D. H. Analysis of nitrogen adsorption isotherms on porous and nonporous silicas by the BET and as methods. J. Colloid Interface Sci. 38(1), 109-119. https://doi.org/10.1016/0021-9797(72)90226-3 (1972).

24. Ravikovitch, P. I., Wei, D., Chueh, W. T., Haller, G. L. \& Neimark, A. V. Evaluation of pore structure parameters of MCM-41 catalyst supports and catalysts by means of nitrogen and argon adsorption. J. Phys. Chem. B 101(19), 3671-3679. https://doi.org/10.1021/ jp9625321 (1997).

25. Khan, M. S., Pal, S. \& Krupadam, R. J. Computational strategies for understanding the nature of interactions in dioxin-imprinted nanoporous trappers. J. Mol. Model. 28(7), 427-437. https://doi.org/10.1002/jmr.2459 (2015).

26. Khan, M. S. \& Krupadam, R. J. Density field theory approach to design multi-template imprinted polymers for carcinogenic PAHs sensing. Comb. Screen. High Throughput Screen. 16(9), 682-694 (2013).

27. Liu, W. et al. Molecularly imprinted polymers on the surface of porous carbon microspheres for capturing dibenzothiophene. Microchim. Acta 183, 1153-1160. https://doi.org/10.1007/s00604-016-1746-2 (2016).

28. Luo, S., Miao, Y., Guo, J. Sun. \& X \& Yan, G. Phosphorimetric determination of 4-nitrophenol using mesoporous molecular imprinting polymers containing manganese(II)-dopes ZS quantum dots. Microchim. Acta 186, 249. https://doi.org/10.1007/s00604-0193362-4 (2019).

29. Sun, X. Y., Ma, R. T., Chen, J. \& Shi, Y. P. Magnetic boronate modified molecularly imprinted polymers on magnetite microspheres modified with porous $\mathrm{TiO}_{2}\left(\mathrm{Fe}_{2} \mathrm{O}_{3} @ \mathrm{pTiO} \mathrm{Ti}_{2} @ \mathrm{MIP}\right)$ with enhanced adsorption capacity for glycoproteins and with wide operational $\mathrm{pH}$ range. Microchim. Acta 185, 565. https://doi.org/10.1007/s00604-018-3092-z (2018).

30. Drewniak, S. et al. Studies of reduced graphene oxide and graphite oxide in the aspect of their possible application in gas sensors. Sensors 16(1), 103-119. https://doi.org/10.3390/s16010103 (2016). 
31. Tobler, D. J., Shaw, S. \& Benning, L. G. Quantification of initial steps of nucleation and growth of silica nanoparticles: An in-situ SAXS and DLS study. Geochim. Cosmochim. Acta 73(18), 5377-5393. https://doi.org/10.1016/j.gca.2009.06.002 (2009).

32. James, A. D. \& Driskell, J. D. Monitoring gold nanoparticle conjugation and analysis of biomolecular binding with nanoparticle tracking analysis (NTA) and dynamic light scattering (DLS). Analyst 138, 1212-1218. https://doi.org/10.1039/C2AN36467K (2013).

33. Zhu, S. et al. Photoluminescence mechanism in graphene quantum dots: Quantum confinement effect and surface/edge state. Nano Today 13, 10-14. https://doi.org/10.1016/j.nantod.2016.12.006 (2017).

34. Van Geen, A. et al. Reliability of a commercial kit to test groundwater for arsenic in Bangladesh. Environ. Sci. Technol. 39(1), 299-303. https://doi.org/10.1021/es0491073 (2005).

35. Sankararamakrishnan, N., Chauhan, D., Nickson, R. T., Tripathi, R. M. \& Iyengar, L. Evaluation of two commercial field test kits used for screening of groundwater for arsenic in Northern India. Sci. Total Environ. 401(1-3), 162-167. https://doi.org/10.1016/j. scitotenv.2008.03.042 (2008)

36. Love, J. L. Chemical metrology, chemistry and the uncertainty of chemical measurements. Accredit. Qual. Assur. 7, 95-100. https:// doi.org/10.1007/s00769-001-0438-7 (2002).

\section{Acknowledgements}

Authors acknowledge financial support of Council of Scientific and Industrial Research (CSIR), New Delhi for financial support.

\section{Author contributions}

M.D. Sharma: Investigation, Final draft S.S. Rayalu: Formal analysis, Resources. S.D. Kolev: Formal analysis, Final draft review and editing. R.J. Krupadam: Conception, planning, design of experiments, final draft-review and editing and supervision. All authors approved final version of the manuscript and this manuscript has been given endorsement for publication by the Institutional authorities.

\section{Competing interests}

The authors declare no competing interests.

\section{Additional information}

Correspondence and requests for materials should be addressed to R.J.K.

Reprints and permissions information is available at www.nature.com/reprints.

Publisher's note Springer Nature remains neutral with regard to jurisdictional claims in published maps and institutional affiliations.

(c) (i) Open Access This article is licensed under a Creative Commons Attribution 4.0 International License, which permits use, sharing, adaptation, distribution and reproduction in any medium or format, as long as you give appropriate credit to the original author(s) and the source, provide a link to the Creative Commons licence, and indicate if changes were made. The images or other third party material in this article are included in the article's Creative Commons licence, unless indicated otherwise in a credit line to the material. If material is not included in the article's Creative Commons licence and your intended use is not permitted by statutory regulation or exceeds the permitted use, you will need to obtain permission directly from the copyright holder. To view a copy of this licence, visit http://creativecommons.org/licenses/by/4.0/.

(c) The Author(s) 2021 